\title{
Ultrametric model for covid-19 dynamics: an attempt to explain slow approaching herd immunity in Sweden
}

\author{
Andrei Khrennikov \\ Linnaeus University, International Center for Mathematical Modeling \\ in Physics and Cognitive Sciences Växjö, SE-351 95, Sweden
}

July 2, 2020

\begin{abstract}
We present a model of infection dynamics that might explain slower approaching the herd immunity during the covid-19 epidemy in Sweden than it was predicted by a variety of other models; see graphs Fig. 2. The new model takes into account the hierarchic structure of social clusters in the human society. We apply the well developed theory of random walk on the energy landscapes represented mathematically with ultrametric spaces. This theory was created for applications to spin glasses and protein dynamics. To move from one social cluster (valley) to another, the virus should cross a social barrier between them. The magnitude of a barrier depends on the number of social hierarchy's levels composing this barrier. As the most appropriate for the recent situation in Sweden, we consider linearly increasing (with respect to hierarchy's levels) barriers. This structure of barriers matches with a rather soft regulations imposed in Sweden in March 2020. In this model, the infection spreads rather easily inside a social cluster (say working collective), but jumps to other clusters are constrained by social barriers. This model's feature matches with the real situation during the covid-19 epidemy, with its cluster spreading structure. Clusters need not be determined solely geographically, they are based on a number of hierarchically ordered social coordinates. The model differs crucially from the standard models of spread of disease, such as the SIR-model. Our model describes such a specialty of spread of covid-19 virus as the presence of "super-infectors" who by performing a kind of random walk on a hierarchic landscape
\end{abstract}




\footnotetext{
${ }^{1}$ In particular, the mathematical model of covid-19 epidemy dynamics of Tom Britton that was used by Swedish State Health Authority predicted that the herd immunity will be approached already in May.

${ }^{2}$ As is well known and widely debated in mass-media, the Swedish government chosen its own way to handle covid-19 epidemy, namely, without any kind of lock-down. The main aim of such a policy is approaching the herd immunity, see appendixes 1,2 for some details.
}

of social clusters spreads infection. In future, this model will be completed by adding the SIR-type counterpart. But, the latter is not a specialty of covid-19 spreading.

keywords: covid-19, epidemy, infection spreading, herd immunity, hierarchy of social clusters, energy landscapes, random walk, trees, ultarmetric spaces, social barriers, linear growing barriers

\section{Introduction}

The dynamics of propagation of the covid-19 pandemy has many unusual features that were not reflected by classical modeling of epidemic dynamics (see, e.g., [1]-[4]). In spite the tremendous efforts [5]-[11], we still do not have a mathematical model describing adequately this dynamics. In this complex situation, one can consider models reflecting some specialties of propagation of covid-19 infection throughout the human society. This paper is a step in this direction. We want to explain essentially slower than expected approaching the herd immunity ${ }^{1}$ in Swedish population (see, e.g., [12]-[14] for reports from Public Health Institute of Sweden, [7]-[9] for attempts of mathematical modeling and [32]-[36] for reports from massmedia). ${ }^{2}$ Our model is purely theoretical. It is based on the advanced mathematics, theory of random walks on hierarchic structures. We use the results of the well known paper [19] on random walk on $p$-adic trees, the simplest hierarchic structures endowed with ultrametric.

The main output that can be interesting say for epidemiologists are the graphs presented in section 4 showing $t^{-a}$ dynamics of probability to be infected in clustered society. The model differs crucially from the standard models of spread of disease, such as the SIR-model [4]. Our model describes such a specialty of spread of covid-19 virus as the presence of "super-infectors" who by performing a kind of random walk on a hierarchic landscape of social clusters spreads infection. In future, this model will be completed by adding the SIR-type counterpart. But, the latter is not a specialty of covid-19 spreading. We hope that this paper may attract attention of experts in epidemiology 
and sociology (the model explores the structure of social connections in the society) who may stimulate its further development.

Our basic assumption (that, in fact, led to consideration of the ultrametric mathematical model) is that infection's distribution in the society has the structure of disjoint social clusters. Such a cluster can be a collective of some enterprise or a state department, say clerks of community office of some town or the personal of some hospital. Inside such a cluster people still have relatively high degree of social connections (see appendix 2). However, even the mild isolation policy of Swedish authorities erected sufficiently high barriers between clusters, because people terminated many sorts of social contacts. In particular, the government did not recommend travels inside the country or abroad. (They were not strictly forbidden, but the majority of citizens followed these recommendations.) Another characteristic feature of the model is that connections between social clusters that can be used by the virus to spread have the hierarchic structure. For example, the community office has higher level in the social hierarchy than the working place. Any worker can have some things to do with community even during the period of epidemy.

Thus the basic assumption of our model is the following one:

Assumption: Infection distribution in population has the hierarchic social cluster structure.

Starting with this assumption, we design a mathematical model implying

Consequence 1. Slower than predicted approaching of the herd immunity.

Consequence 2. Slow decay of epidemy.

The problem of approaching the herd immunity is especially important in the light of Swedish experience and its consequences for states' policies in preparation to the second wave of covid-19 or other similar viruses. The herd immunity is mathematically formalized through the average probability for a person to become infected at time $t, P_{I}(t)$.

To model cluster dynamics, we use random walk on ultrametric spaces [19]. It was widely used in studied in physics and microbiology, see [19], [20]-[25] and references herein. Geometrically ultrametric spaces have the treelike structure. The simplest trees are homogeneous trees with the fixed number of branches $p$ leaving each vertex, $p$-adic trees.

Random walks on trees describe dynamics on energy landscapes. There are given energy barriers $\Delta_{m}$ separating valleys, movement from 
one valley to another valley is constrained by necessity to jump over a barrier between them.

In our model of the covid-19 epidemy, originally the virus (or its carrier) is perform a random walk in socially clustered society, it spreads relatively easily inside a clustee, but to approach other social clusters it should "jump over social barriers". Dynamics depends heavily on two parameters: on the magnitudes of the social barriers (the type of their growth between different levels of hierarchy) and on the social analog of temperature. The magnitude of a social barrier depends only on the number of hierarchy levels composing it, not on a social cluster. This is the very important constraint on the population, it should be sufficiently homogeneous socially. (In spite of the recent waves of immigration, Swedish society is still socially very homogeneous.)

The configuration space of dynamics is the tree of social connections between people. In epidemy modeling, it is natural to assume the presence of the hierarchic structure in social clustering of people, by ranging basic social parameters coupled to infection. This representation of individuals, as vectors of hierarchically ordered social coordinates have been already used by the author and his collaborators in a series of studies in cognition and psychology [26]-[31].

Just before submission of this preprint, I discovered the recent paper of Britton et al. [15]. One of its authors, Britton, initiated intensive mathematical modeling of spreading of covid-19 in Sweden and, in particular, he is famous in Sweden for his prognoses of approaching herd immunity in Swedish population [7]-[9]. These prognoses did not match with the real data. In the new modeling [15], Britton et al. started to take into account heterogeneity of population (cf. [16]-[18]). This is a step towards coupling with our model. Before to discuss similarities and differences of two models in more detail, I should study article [15] more carefully.

\section{Social trees}

We represent the human society as a system of hierarchically coupled disjoint clusters. There are many ways of creation of such representations. We present one of these possibilities that was used in my works of ultrametric modeling in cognition and sociology (see, e.g., [26]-[30]). The treelike representation of social types is based on selection of hierarchically ordered social factors enumerated as $m=0,1,2,3, \ldots$; factor $m=0$ is the most important, $m=1$ is less important and so on. A 
social type is represented by a vector

$$
x=\left(x_{0}, x_{1}, \ldots, x_{n-1}\right),
$$

where its coordinates $x_{m}$ take (typically) discrete values quantifying the $m$-th factor. In the simplest case, $x_{m}$ takes two values, "yes" / "no", or $1 / 0$. We call numbers $\left(x_{m}\right)$ social coordinates. The vector representation of social types and individuals is widely used in sociology and psychology. The main distinguishing feature of our model is endowing the space of vectors with the special metric reflecting the hierarchic structure corresponding the order of social factors (see, e.g., [26]-[30] on application to cognition and psychology). The space of all vectors of the form (4) is called the hierarchic social space.

Since in the covid-19 situation the state plays the crucial role as the policy determining organ, it is natural to select $m=0$ as the state that population is under consideration. However, since the majority of states selected the lock down policy that was not oriented towards approaching the herd immunity, we restrict consideration to the Swedish population and use $m=0$ for the next basic social factor, namely, for individual's age, then say $m=1$ for the presence of one chronic diseases, $m=2$ for gender, $m=3$ for race, $m=4$ for the town of location, $m=6$ for profession, $m=7$ for the level of social activity, $m=5$ the district in the town, $m=8$ for the number of children, and so on. We understand that such ranking of the basic social factors related to the covid-19 epidemy may be naive and incomplete. The contribution of sociologists, psychologists, and epidemiologists can improve the present model essentially.

For mathematical simplicity, we consider $p$-adic coordinates, $x_{m}=$ $0,1, \ldots, p-1$, where $p>1$ is a prime number. The space of all such vectors denote by the symbol $Z_{p ; n}$ ( $p$ is fixed). For analytical computations, it is convenient to represent elements of this space by natural numbers

$$
x=x_{0}+x_{1} p+x_{1} p^{2}+x_{n-1} p^{n-1}, x_{m} \in\{0,1, \ldots, p-1\} .
$$

Thus the points of the hierarchic social space can be represented by natural numbers, $Z_{p ; n}=\left\{0, \ldots, p^{n}-1\right\}$. The number of its points grows exponentially with the number of social coordinates $n$.

We now turn to the definition of a metric on $Z_{p ; n}$. Consider two social vectors $x=\left(x_{1}, \ldots, x_{n-1}\right)$ and $y=\left(y_{1}, \ldots, y_{n-1}\right)$. Let their firts $k$ coordinates are equal, $x_{0}=y_{0}, \ldots, x_{k-1}=y_{k-1}$, but the $k$ th coordinates are different, $x_{k} \neq y_{k}$. Then the hierarchic social distance between these social types, $d(x, y)=n-k$. The first social coordinates are the most important: longer the common initial segment of vectors 
corresponds to closer social type, increase of $k$ implies decrease of distance between two social types. For example, let $k=n-1$, i.e., two points differ only in the last coordinate, then $d(x, y)=1$. This is the minimal possible distance in $Z_{p ; n}$. (The coordinate $x_{n}$ has the minimal degree of importance.) If the vectors differ already by the first coordinate, i.e., $x_{0} \neq y_{0}$, then $d(x, y)=n$. This is the maximal possible distance between points in space $Z_{p ; n}$. Distance $d$ is ultrametric, it satisfies the strong triangle inequality:

$$
d(x, y) \leq \max \{d(x, z), d(y, z)\},
$$

for any triple of points $x, y, z \in Z_{p ; n}$. Here in each triangle, the third side is less or equal not only to the sum of two other sides (as usual), but even to their maximum.

As usual in a metric space we can introduce balls, $B_{N}(a)=\{x \in$ $\left.Z_{p ; n}: d(a, x) \leq N\right\}$, where $N=1, \ldots, n$, and $a=\left(a_{0}, . .,, a_{n-1}\right)$ is some point in $Z_{p ; n}$, ball's center. In an ultrametric space, any two balls are either disjoint or one is contained in another and any point of a ball can be selected as its center.

For our modeling, it is important that the space $Z_{p ; n}$ can be split into disjoint social clusters. (As we shall see soon, these clusters are, in fact, balls.) Each cluster is determined by fixing a few first (the most important) social coordinates,

$$
Z_{p ; n}=\cup_{j=0}^{p-1} C_{j},
$$

where $C_{j}=\left\{x: x_{0}=j\right\}$. This cluster representation corresponds to the first level of social hierarchy, we distinguish points by their most important coordinate. Each of clusters $C_{j}$ can be represented similarly as

$$
C_{j}=\cup_{j=0}^{p-1} C_{j i},
$$

where $C_{j i}=\left\{x: x_{0}=j, x_{1}=i\right\}$ are clusters of the deeper hierarchic level and so on, up to the single-point clusters corresponding to fixing all social coordinates.

Clusters are, in fact, ultrametric balls:

$$
C_{i_{0} \ldots i_{k}-1}=\left\{x: x_{0}=i_{0}, \ldots, x_{k-1}=i_{k-1}\right\}=B_{n-k}(a),
$$

where $a$ is any point of the form $a_{0}=i_{0}, \ldots, a_{k-1}=i_{k-1}$ and arbitrary coordinates $a_{j}, j=k, \ldots, n-1$.

Geometrically space $Z_{p ; n}$ is represented as a homogeneous tree with $p$ branches leaving each vertex. Cluster is a bunch of branches having the common root. By extending this root we split the cluster into subclusters. 
Now we consider the procedure of extension of a social tree by adding new social coordinates, so from tree $Z_{p ; n}$ to tree $Z_{p ; N}$, where $N>n$. As the result of such an extension, each point of social space $Z_{p ; n}$ becomes a social cluster in social space $Z_{p ; N}$. In principle, it is impossible to determine a social type by fixing any finite number of social coordinates. Hence, We have to consider infinite sequences of coordinates:

$$
x=\left(x_{0}, x_{1}, \ldots, x_{n-1}, \ldots\right), x_{j}=0,1, \ldots, p-1 .
$$

Denote the space of such sequences by the symbol $Z_{p}$. This is the complete hierarchic social space. Points of finite trees represent social clusters.

\section{Dynamics}

Consider a tree with $n$ levels of social hierarchy, $Z_{p ; n}$. Suppose that initially infected people are concentrated just in one social cluster represented by a single point of $x \in Z_{p ; n}$. Consider the initial probability for a person in this cluster to become infected, $P(y, 0)=\delta(y-x)$.

The virus plays the role of a system moving through barriers in models of dynamics on energy landscapes (see [19], [20]-[25] and references herein). In our case, these are social barriers between social clusters of population. The virus performs a complex random walk motion inside each social cluster moving in its sub-clusters, goes out of it and spreads through the whole population, sometimes the virus comes back to the original cluster from other social clusters that have been infected from this initial source of infection, and so on. During this motion the virus should cross numerous social barriers.

Instead of virus walking through the social tree, we can consider a person. A person of the social type $x=\left(x_{1}, \ldots, x_{n}\right)$ can interect with persons of the social type, $y=\left(x_{1}, \ldots, x_{k}-1, y_{k}, \ldots, y_{n}\right)$, where $x_{k} \neq y_{k}$ by crossing the social barrier for $n-k$ levels of hierarchy. The temporal sequence of social contacts of some persons can have a very complicated trajectory, visiting numerous clusters (but the probability of approaching a cluster depends crucially on social barriers).

We are interested in the relaxation process that is understood as the evolution of the probability to become infected for a person from the social cluster $x$, i.e., in the time dependence of the quantity $P(x, t)$.

We do not want to go into details, since the problem of relaxation was well studied in physics and microbiology, see [19], [20]-[25] and references herein. The relaxation regime depends crucially on the barriers' magnitude, how rapidly they grow up on the way from one cluster to another. 


\section{Random walk on on infinite trees: temporal behavior of probability}

As in the previous section, we a random walk on a finite tree. Here we follow the paper of Ogielski [19]. Let us consider a finite tree with $n$ levels. Thus there are $2^{n}$ points at the last level. They enumerate the total population: $i=0, \ldots, 2^{n}-1$.

Let virus encounters a barrier of size $\Delta_{m}$, in hopping a distance $m$ ( for crossing $m$ levels of hierarchy), where $\Delta_{1}<\Delta_{2}<\ldots<\Delta_{m}<\ldots$. It is supposed that barriers $\Delta_{m}$ are the same for all social clusters, i.e., they depend only on distance, but not on clusters.

The probability to jump over the barrier $\Delta_{m}$ has the form (up to the normalization constant):

$$
\mathbf{P}(m)=e^{-\frac{\Delta m}{T}},
$$

where $T$ is model's parameter; in physics it has the meaning of temperature of the environment; we also interpret it similarly, as a kind of social temperature, cf. [?]. Probability $\mathbf{P}(m)$ increases (for crossing the fixed number of hierarchy's levels) with increasing of social temperature $T$. For high social temperatures, jumps are easier.

The simplest one is that with a uniform barrier $\Delta$, at every branch point; that is, a jump of distance 1 involves surmounting a barrier $\Delta$, of distance 2 , a barrier $2 \Delta$, and so on. Hence, barriers linearly grow with distance $m$,

$$
\Delta_{m}=m \Delta, m=1,2, \ldots .
$$

It seems that this type of behavior is the most natural from the viewpoint of social connections during the covid-19 epidemy in Sweden. Barriers are sufficiently high, but they still are not walls as during the rigid quarantine (as say in Italy, France, or Russia). The probability to jump over the barrier $\Delta_{m}$ has the form (up to the normalization constant):

$$
\mathbf{P}(m)=e^{-\frac{m \Delta}{T}} .
$$

The probability depends on the height $\Delta$ of the minimal social barrier, but, for large $m$, its contribution to is not so important.

By using random walk on the tree with $n$ levels of hierarchy and approaching $n \rightarrow \infty$ one can derive the following asymptotic behavior of the relaxation probability:

$$
P(x, t)=t^{-T \ln p / \Delta}, t \rightarrow \infty .
$$

Set $\kappa=T \ln p / \Delta$. If $\kappa<<1$, e.g., the social temperature is low, $p$ is small say $p=2$ and the primary social barrier $\Delta$ is large, then the 


\footnotetext{
${ }^{3}$ See appendix 1; finally, the state epidemiologist Anders Tegnell pointed that it seems meaningless to appeal to mathematical models at all, since they do not reflect even approximately the real situation.
} average probability for a person in the original social cluster $C_{0}$ to become infected decreases rather slowly, see Fig. 1.

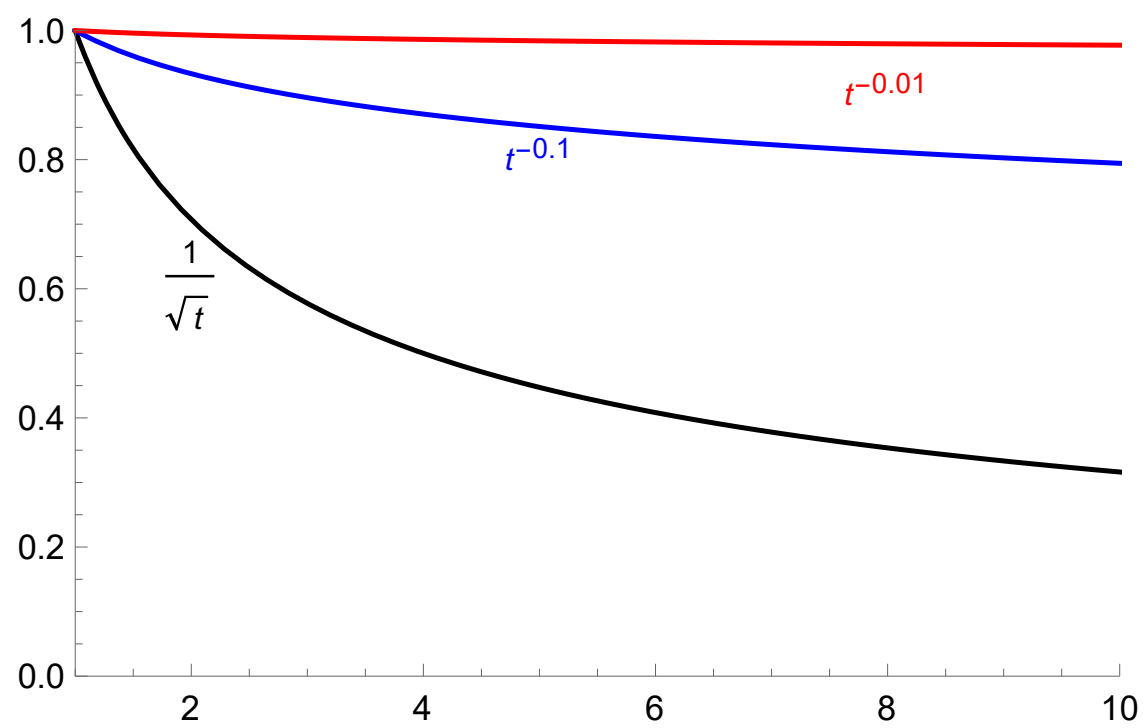

Figure 1: Asymptotic behavior of probability $\mathrm{P}(\mathrm{x}, \mathrm{t})$ to become infected. (For fixed social temperature $T$, the upper graphs correspond to one-step barrier growth 10 and 100 times, respectively.

Hence immunity against covid-19 increases also slowly, see Fig. 2, as function

$$
1-P_{I}(x, t) \sim 1-t^{-T \ln p / \Delta}, t \rightarrow \infty .
$$

\section{Concluding remarks}

The presented ultarmetric model with random walk dynamics on energy landscapes describes well the social cluster structure of spreading of covid-19. The model was designed to explain mathematically the slow approaching the herd immunity in Swedish population during March-June 2020, essentially slower than it was predicted by all mathematical models. ${ }^{3}$ The model elevates the role of the social dimension of infection spreading comparing with its purely bio-medical dimension. The bio-medical restrictions in Sweden were very soft; in particular, no face-masks, 1,5 meter social distance, public transportation worked more or less as usual (see appendix 2 for details). The 


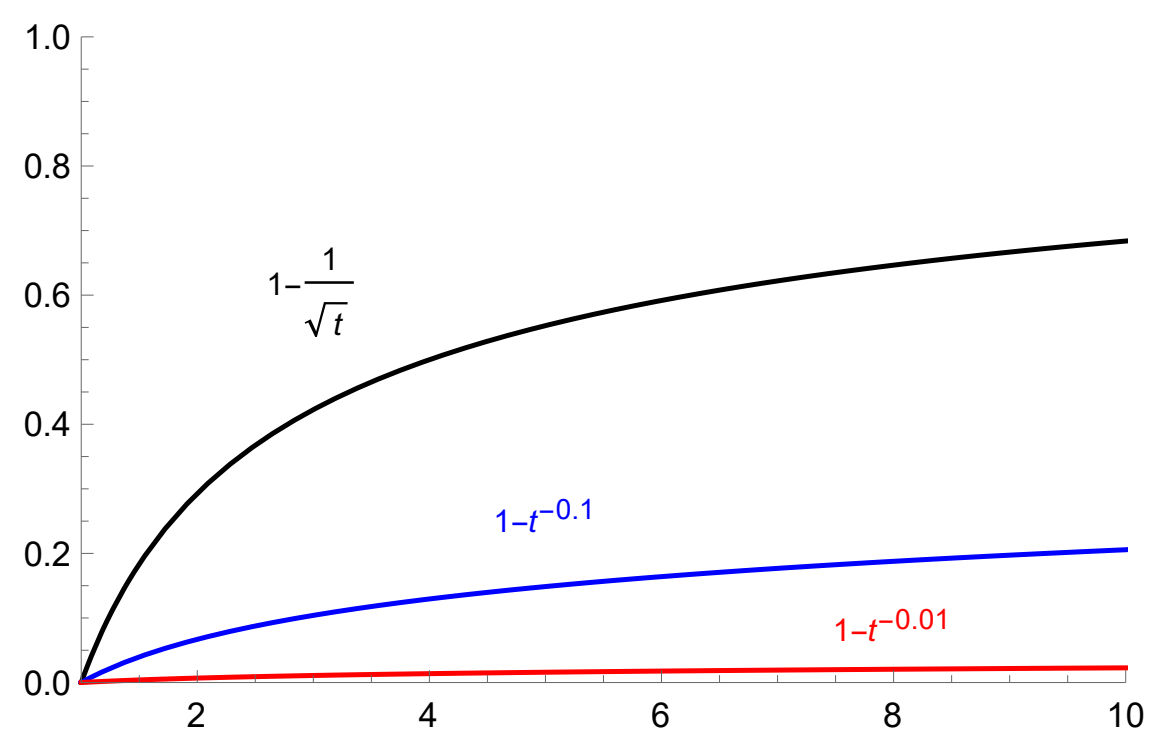

Figure 2: Asymptotic behavior of probability to become immune; increasing of the herd immunity (for fixed social temperature $T$, the upper graphs correspond to one-step barrier growth 10 and 100 times, respectively.

most typical infecting took place in working collectives in that social contacts were not occasional, as say in metro, or in a bus, or even in a restaurant during lunch, but close and permanent, on the everyday basis.

We applied to the new area of research, to epidemiology, mathematical theory developed for applications in statistical physics (spin glasses) and microbiology (protein folding): ultrametric random walk describing dynamics on complex energy landscapes with the hierarchic structure of barriers between valleys. The presence of social barriers growing with hierarchy's levels makes the evolution of epidemy essentially slower than in models which do not take into account the cluster-character of infection spreading. In particular, our model is purely diffusional, cf. with starndard SIC-model []. We motivate consideration of linearly growing social barriers in Sweden with its soft epidemiological restrictions.

Although the model is very simplified it reflects some features of the covid-19 epidemy in Sweden. We hope that it will stimulate further development of ultrametric epidemiological models taking into account the hierarchic social clustering of population. 


\section{Appendix 1: Growth of the herd immu- nity in Sweden}

Our model can be interesting only for Sweden, where the "experiment" for approaching the herd immunity was performed in its clean form, without overshadowing by quarantine. The main concern of Swedish authorities, including Anders Tegnell, is that the dynamics of getting antibodies for covid-19 in Swedish population is essentially slower than it was expected. Since the end of April 2020, Anders Tegnell, the chief state epidemiologist of Sweden, started to announce (see, e.g., [32]) that very soon we, Swedish citizens, will become immune against the virus. This announcement was repeated a few times during May-June 2020, but it still not clear whether it happened or not (see, e.g., [34][36]). Moreover, Stockholm university made recently (June 24 []) the update that, in fact, already the level $60 \%$ can be considered as the herd immunity state. So, it seems that there is no hope to approach $70 \%$ level of immunity.

On June 24, 2020, it was announced [] that: "A total of 7.3 percent of the blood samples collected from people in Stockholm were positive, 4.2 percent in Skane and 3.7 percent in Västra Götaland. The numbers reflect the situation in early April, as it takes time for the antibodies to develop. The authority's modeling has previously shown that 26 percent of the population in Stockholm would have been infected on May 1. Tom Britton, professor of mathematical statistics at Stockholm University, comments on these and says that the figures are "clearly lower", than he thought. "Firstly, I am thinking about the modeling, if there is any mistake that I and the Public Health Authority have made. Then you also wonder if some have been infected but do not have detectable antibodies, for example people who are mildly infected."

The level of the herd immunity depends on the age group. On June 2, 2020, it was pointed out that for the youngsters up to 19 years old around $8 \%$ Andelen med antikroppar mot covid-19 bland yngre upp till 19 år var närmare åtta procent, för åldersgruppen 2064 låg motsvarande siffra på 6-7 procent. För personer över 65 år låg siffran på cirka tre procent. Det kan finnas flera skäl till att det är lägre nivåer för vuxna och äldre, enligt Karin Tegmark Wisell. 


\section{Appendix 2: Situation in Sweden and approaching the herd immunity}

Comparing with the majority of other countries the Swedish preventing measures look as very smooth:

- The number of participants of any meeting (social, business, science, sport, children activity) should not exceed 50 persons.

- It was not recommended (but not forbidden) to make travels inside Sweden and abroad without special need (private or on business).

- For old people, it was suggested to escape social contacts, but the decision was up to each individual.

- In restaurants, night clubs, and disco, people should keep a "social distance".

It is clear that such minor measures cannot stop spreading of covid-19. The aim was just to make spreading slower and in this way to much the capacity of hospitals and the speed of virus' spreading. This antiepidemic policy has its own advantages and disadvantages and we do not plan to discuss them in this paper that is aimed to model mathematically approaching of the herd immunity in Sweden. Generally the herd immunity is the well established topic of the epidemiological research, so, in principle, there is nothing specially Swedish in its modeling. The specialty of the present pandemy is that only the Swedish state epidemiologist Anders Tegnell selected teh strategy of approaching of a high level of immunity to covid-19 in Swedish population. Theoretically a population becomes secure against some decease when around $70 \%$ of it becomes immune against this decease.

Although in numerous interviews Tegnell always rejects that the aim of his policy is to infect as many people as possible, it seems that in reality the aim was precisely this one. One of the signs of such aiming was soft control of how population is even aforementioned minor restrictions. As one may be have seen from reportage from Sweden, streets, even in Stockholm (it was epidemy's epicenter in Sweden), were crowded by walking people who even did not keep the recommended social distance $1.5 \mathrm{~m}$, the same could be seen in restaurants. There were some stories that in Stockholm some restaurants were closed, because their owners did follow the recommendations, but in my own town Växjö (around 100000 people) people seat very dense, especially during business or family events; moreover, I (by taken launches) have seen really very old people who were eating and drinking wine (well, may be the last glass wine?). Another signal that 
Sweden was aiming to approach the herd immunity was the permanent pointing by Tegnall to the second wave of covid-19 and that the herd immunity would help us to pass this new disaster easier than population of countries selected the policy of lockdown.

\section{References}

[1] R. M. Anderson, R. M. May, Infectious Diseases of Humans: Dynamics and Control (Oxford Univ. Press, 1991).

[2] H. Andersson, T. Britton, Stochastic Epidemic Models and Their Statistical Analysis (Springer, 2000).

[3] O. Diekmann, H. Heesterbeek, T. Britton, Mathematical Tools for Understanding Infectious Disease Dynamics (Princeton Univ. Press, 2013).

[4] D. Smith and L. Moore, The SIR Model for Spread of Disease - The Differential Equation Model. https://www.maa.org/press/periodicals/loci/joma/the-sirmodel-for-spread-of-disease-the-differential-equation-model.

[5] S. Flaxman, S. Mishra, A. Gandy, H. J. T. Unwin, H. Coupland, T. A. Mellan, H. Zhu, T. Berah, J. W. Eaton, P. N. P. Guzman, N. Schmit, L. Cilloni, K. E. C. Ainslie, M. Baguelin, I. Blake, A. Boonyasiri, O. Boyd, L. Cattarino, C. Ciavarella, L. Cooper, Z. Cucunubá, G. Cuomo-Dannenburg, A. Dighe, B. Djaafara, I. Dorigatti, S. van Elsland, R. FitzJohn, H. Fu, K. Gaythorpe, L. Geidelberg, N. Grassly, W. Green, T. Hallett, A. Hamlet, W. Hinsley, B. Jeffrey, D. Jorgensen, E. Knock, D. Laydon, G. Nedjati-Gilani, P. Nouvellet, K. Parag, I. Siveroni, H. Thompson, R. Verity, E. Volz, C. Walters, H. Wang, Y. Wang, O. Watson, P. Winskill, X. Xi, C. Whittaker, P. G. T. Walker, A. Ghani, C. A. Donnelly, S. Riley, L. C. Okell, M. A. C. Vollmer, N. M. Ferguson, S. Bhatt, Report 13: Estimating the number of infections and the impact of non-pharmaceutical interventions on COVID-19 in 11 European countries (Imperial College London, 2020); .doi:10.25561/77731

[6] N. M. Ferguson, D. Laydon, G. Nedjati-Gilani, N. Imai, K. Ainslie, M. Baguelin, S. Bhatia, A. Boonyasiri, Z. Cucunubá, G. Cuomo-Dannenburg, A. Dighe, I. Dorigatti, H. Fu, K. Gaythorpe, W. Green, A. Hamlet, W. Hinsley, L. C. Okell, S. van Elsland, H. Thompson, R. Verity, E. Volz, H. Wang, Y. Wang, P. G. T. Walker, C. Walters, P. Winskill, C. Whittaker, C. A. Donnelly, S. 
Riley, A. C. Ghani, Report 9: Impact of non-pharmaceutical interventions (NPIs) to reduce COVID-19 mortality and healthcare demand (Imperial College London, 2020); 10.25561/77482.doi

[7] T. Britton, Basic estimation-prediction techniques for Covid19, and a prediction for Stockholm. Preprint, April 2020 DOI: $10.1101 / 2020.04 .15 .20066050$

[8] T. Britton, Basic estimation-prediction techniques for Covid-19, and a prediction for Stockholm. https://www.medrxiv.org/content/10.1101/2020.04.15.20066050v2

[9] T. Britton, P. Trapman, F.G. Ball, The diseaseinduced herd immunity level for Covid-19 is substantially lower than the classical herd immunity level. https://www.medrxiv.org/content/10.1101/2020.05.06.20093336v2

[10] W. Bock, B. Adamik, M. Bawiec, V. Bezborodov, M. Bodych, J. P. Burgard, T. Goetz, T. Krueger, A. Migalska, B. Pabjan, T. Ozanski, E. Rafajlowicz, W. Rafajlowicz, E. SkubalskaRafajlowicz, S. Ryfczynska, E. Szczurek, P. Szymanski, Mitigation and herd immunity strategy for COVID-19 is likely to fail. medRxiv 2020.03.25.20043109 [Preprint]. 5 May 2020; .doi:10.1101/2020.03.25.20043109 Abstract/FREE Full TextGoogle Scholar

[11] H. Salje, C. T. Kiem, N. Lefrancq, N. Courtejoie, P. Bosetti, J. Paireau, A. Andronico, N. Hozé, J. Richet, C.-L. Dubost, Y. Le Strat, J. Lessler, D. Levy-Bruhl, A. Fontanet, L. Opatowski, P.-Y. Boelle, S. Cauchemez, Estimating the burden of SARS-CoV-2 in France. Science 10.1126/science.abc3517 (2020). doi:10.1126/science.abc3517

[12] Public Health Institute of Sweden, Estimates of the peak-day and the number of infected individuals during the covid-19 outbreak in the Stockholm region, Sweden February-April 2020 [in Swedish] (2020); www.folkhalsomyndigheten.se/contentassets/2da059f90b90458d8454a04955d1697f/skattning peakdag-antal-infekterade-covid-19-utbrottet-stockholms-lanfebruari-april-2020.pdf.

[13] Public Health Institute of Sweden: Antikroppstester avviker fran prognoserna - matematikern "ser tva förklaringar". https://www.svt.se/nyheter/inrikes/antikroppstester

[14] Public Health Institute of Sweden: Yngre personer har högre andel antikroppar. Sverige Radion, June 2, 20202; https://sverigesradio.se/sida/artikel.aspx?programid $=83$ artikel $=7487102$ 
[15] T. Britton, F. Ball, P. Trapman, A mathematical model reveals the influence of population heterogeneity on herd immunity to SARS-CoV-2. Science 23 Jun 2020: eabc6810

[16] J. Wallinga, P. Teunis, M. Kretzschmar , Using data on social contacts to estimate age-specific transmission parameters for respiratory-spread infectious agents. Am. J. Epidemiol. 164, 936-944 (2006).

[17] R. Pastor-Satorras, A. Vespignani, Epidemic spreading in scalefree networks. Phys. Rev. Lett. 86, 3200-3203 (2001).

[18] M. J. Ferrari, S. Bansal, L. A. Meyers, O. N. Bjørnstad, Network frailty and the geometry of herd immunity. Proc. Biol. Sci. 273, 2743-2748 (2006).

[19] A. T. Ogielski, Dynamics on Ultrametric Spaces. PHYSICAL REVIEW LETTERS, 55, N 15, 1634-1637.

[20] M. Mezard, G. Parisi, N. Sourlas, G. Toulouse, and M. Virasoro, Phys. Rev. Lett. 52, 1156 (1984).

[21] R. G. Palmer, Adv. Phys. 31, 66a (1982); G. Parisi, Phys. Rev. Lett. 50, 1946 (1983).

[22] A. Ansari, J. Berendzen, S. F. Bowne, H. Frauenfelder, I. E. T. Iben, T. B. Sauke, E. Shyamsunder, and R. D. Young, Proc. Natl. Acad. Sci. USA 82, 5000 (1985).

[23] R. G. Palmer, D. L. Stein, E. Abrahams, and P. W. Anderson, Phys. Rev. Lett. 53, 958 (1984).

[24] B. A. Huberman and M. Kerszberg, J. Phys. A 18, L331 (1985).

[25] Parisi, Phys. Rev. Lett. 43, 1754 (1979).

[26] Khrennikov A., Human subconscious as a p-adic dynamical system. Journal of Theoretical Biology, 193(2), 179-96 (1998).

[27] S. Albeverio, A. Khrennikov, P. E. Kloeden, Memory retrieval as a p-adic dynamical system. Biosystems 49, N 2, 105-115 (1999).

[28] D. Dubischar, V. M. Gundlach, O. Steinkamp, A. Khrennikov, A p-Adic Model for the Process of Thinking Disturbed by Physiological and Information Noise. Journal of Theoretical Biology 197(4), 451-67 (1999).

[29] A. Khrennikov, Information Dynamics in Cognitive, Psychological, Social, and Anomalous Phenomena. Kluwer, 2004

[30] A. Khrennikov, Probabilistic pathway representation of cognitive information. Journal of Theoretical Biology 231, N 4, 597-613 (2004). 
[31] A. Khrennikov, Toward an adequate mathematical model of mental space: Conscious/unconscious dynamics on m-adic trees. Biosystems 90, N 3, 656-675 (2007).

[32] Tegnell: "Vi får oroande rapporter om utelivet". SVT, Nyheter, 20-04-2020; https://www.svt.se/nyheter/inrikes/tegnellvi-far-oroande-rapporter-om-utelivet

[33] Se hur matematikprofessorn räknar ut när Stockholm uppnar flockimmunitet. SVT Nyheter, 20-04-2020.

[34] G. Holm, Hoppfulla teorin: Sa når vi flockimmunitet redan i juni. Expressen, 10.05.2020. https://www.expressen.se/nyheter/coronaviruset/hoppfullateorin-sa-nar-vi-flockimmunitet-redan-i-juni/

[35] A. Obminska, Det här vet vi om coronaviruset. Ny Teknik, 3006-20202; https://www.nyteknik.se/samhalle/det-har-vet-vi-omcoronaviruset-6985117

[36] Public Health Institute of Sweden, 18-06-2020; https://www.folkhalsomyndigheten.se/nyheter-ochpress/nyhetsarkiv/2020/juni/forsta-resultaten-om-antikropparefter-genomgangen-covid-19-hos-blodgivare/ 